H A R VAR D B U S I N E S S S S C H O O L

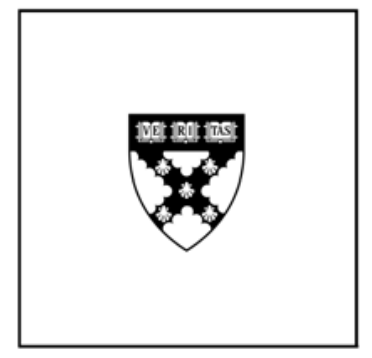

\title{
Asset Specificity and Vertical Integration: Williamson's Hypothesis Reconsidered
}

\author{
Christian A. Ruzzier
}

\section{Working Paper}

09-119 


\title{
Asset Specificity and Vertical Integration: Williamson's Hypothesis Reconsidered ${ }^{1}$
}

\author{
Christian A. Ruzzier ${ }^{2}$ \\ Harvard Business School
}

April 3, 2009

\begin{abstract}
${ }^{1}$ This paper is adapted from Chapter 3 of the author's Ph.D. dissertation at the Toulouse School of Economics. I want to thank my supervisor, Jacques Crémer, as well as Guido Friebel for great advice and support. I gratefully acknowledge comments and suggestions from Daniel Benitez, Hongbin Cai, Robert Gibbons, Maija Halonen, Oliver Hart, Bruno Jullien, Ola Kvaløy, Germán Lambardi, Erik Lindqvist, and audiences at the Université de Toulouse, Universidad de San Andrés, Universidad Torcuato Di Tella, University of Stavanger, Université Paris I Panthéon-Sorbonne, the 2006 ENTER Jamboree 2006, and the 2006 Annual Congress of the European Economic Association. Any remaining mistake is, of course, my own responsibility. A previous version of this paper circulated under the title "Levels of Asset Specificity in Relational Contracting".

${ }^{2}$ Address: 25 Harvard Way, Baker Library | Bloomberg Center 444B, Boston, MA 02163. Phone: +1 (617) 495 0875. E-mail: cruzzier@hbs.edu.
\end{abstract}




\begin{abstract}
A point repeatedly stressed by transaction cost economics is that the more specific the asset, the more likely is vertical integration to be optimal. In spite of the profusion of empirical papers supporting this prediction, recent surveys and casual observation suggest that higher levels of asset specificity need not always lead to vertical integration. The purpose of this paper is to uncover some of the factors driving firms to (sometimes) choose to remain separated, rather than integrate, in the presence of high specificity. Its main economic message is that in a world where outside options matter and investments are multidimensional, high levels of asset specificity can foster nonintegration: a low level of specificity provides the most misdirected incentives when transacting in a market (because the outside option of external trade becomes so tempting), thus making a stronger case for nonintegration when specificity is high.
\end{abstract}

JEL Codes: L14, D23, L24

Keywords: relational contracts, asset specificity, property rights, vertical integration, outsourcing 


\section{Introduction}

A point repeatedly stressed by transaction cost economics (TCE) is that the more specific the asset, the more likely is vertical integration to be optimal. ${ }^{1}$ In spite of the profusion of empirical papers supporting this basic TCE prediction (see the surveys by Macher and Richman, 2008; Masten and Saussier, 2000; and Shelanski and Klein, 1995), recent surveys and casual observation suggest that the relation between specificity and integration may not be as straightforward as suggested in transaction cost theory - that is, higher levels of asset specificity need not always lead to vertical integration.

The survey by Carter and Hodgson (2006), for example, shows that evidence is more mixed than previously claimed; the one by David and Han (2004) reaches a similar conclusion and highlights deficiencies in many existing empirical tests - most notably, that there is no evidence on whether a given integration choice is efficient, and that there are problems with the operationalization and measurement of asset specificity. Woodruff (2002) underlines another potential problem: the empirical finding that specificity increases the benefits of integration is not enough to conclude that higher specificity will lead to more integration - what happens to the cost of integration is also likely to be important, but is an issue that has not been addressed by the existing empirical literature. Woodruff's analysis of the Mexican footwear industry also suggests that TCE explanations may do a poor job in predicting patterns of integration: when some product characteristics change (in the direction of an increased level of specificity), the evidence indicates that integration becomes less frequent. ${ }^{2}$ In addition, Holmström and Roberts (1998) point out many situations where observed ownership patterns are hard to reconcile with transaction cost theory - such as Japanese manufacturing, U.S. steel makers, airline alliances, and the contractual networks in the media, software and biotechnology industries - and Gilson et al. (2009) extensively document how rapidly innovating industries are moving away from integration to deal with transaction-specific investments.

\footnotetext{
${ }^{1}$ The transaction cost approach developed from the work of Williamson (1975) and Klein et al. (1978). Williamson (1985) provides a thorough discussion of the role of asset specificity in the integration decision.

${ }^{2}$ Check also Acemoglu et al. (2007), who show that TCE is not easily reconciled with some of their findings about vertical integration in the UK manufacturing sector.
} 
The purpose of this paper is to uncover some of the factors driving firms to (sometimes) choose to remain separated, rather than integrate, in the presence of high levels of asset specificity. In the model considered, an upstream party uses an asset to produce in each period a good that is valuable both to a downstream party and in an alternative use. As in the property rights approach, asset ownership is the defining characteristic of integration, which will be identified with downstream ownership (and nonintegration with upstream ownership). ${ }^{3}$ The asset is specific in the sense that the value of the good to the downstream party is always larger that its value in the alternative use. The upstream party must make multidimensional investments that affect both these values of internal and external trade, but contracts are incomplete: none of these investments or values can be put into an enforceable contract.

Under integration, the downstream party can simply take the good without any payment after production takes place. Under nonintegration, however, she has to pay a price to the upstream party to secure the good. With incomplete contracts, ex post bargaining is needed to determine this price and to allocate the surplus generated by the relationship. This paper explores the role of outside options in bargaining in a relational contracting setting: each bargainer gets half of the surplus unless this gives one of them strictly less than her outside option (in which case she must receive her outside option, the other party receiving what is left). Contrary to standard property rights theory (but similar to TCE), the paper shows that the integration decision crucially depends on the level of asset specificity, even in the static version of the model. Contrary to TCE, however, it shows how, in a world where outside options matter and investments are multidimensional, high levels of quasi-rents may provide a rationale for nonintegration.

The role of the level of specificity emerges naturally under bargaining with outside options: the bargained price of the good depends on whether or not the outside option is binding, which in turn depends on how the outside option (i.e., the value of external trade) is compared with value within the relationship. Put simply, the upstream party's outside option will not bind as long as the level of asset specificity is high enough. Thus the level of

\footnotetext{
${ }^{3}$ The property rights approach was pioneered by Grossman and Hart (1986) and Hart and Moore (1990), and is probably best presented in Hart's (1995) book.
} 
asset specificity matters: it determines whether the upstream party's threat to quit bargaining and put the good to its alternative use is credible or not, and fundamentally affects the allocation of effort across tasks and, in the dynamic setting, the temptations of either party to renege on a given relational contract. This interplay between multitasking and outside options lies beneath all of the results in this paper.

Regardless of the ownership arrangement, the downstream party would always like the upstream party to take actions that increase the internal value of the good. With one-shot interactions (spot contracting) the only instrument to provide incentives is asset ownership. Giving ownership to the upstream party provides her with stronger incentives to work hard; the allocation of this effort, on the other hand, is determined by the price that results from bargaining under nonintegration. Asset ownership must then strike a balance between encouraging and directing the multidimensional actions taken by the investing (upstream) party. $^{4}$

With repeated interaction there is an additional instrument to provide and direct incentives under both ownership regimes: bonuses based on the value of the good. Because bonuses are informal promises that must be self-enforcing, however, there are limits to what can be credibly promised. Matters are more complex under such relational contracting since the spot outcomes now form the punishments triggered by a defection, and both defection incentives (or reneging temptations) and punishment payoffs depend on the ownership arrangement.

My main result is that under bargaining with outside options the first best is easier (harder) to achieve with relational nonintegration than with relational integration when the degree of asset specificity is high (low). Hence, high levels of quasi-rents can provide a rationale for nonintegration. The bonuses that deliver the first-best outcome generate the smallest (largest) temptation to renege on the relational contract under nonintegration when asset specificity is high (low). This also implies that for some discount rates the first best is achievable under one ownership structure, but not under the other, depending on the level of asset specificity.

That reputational forces can weaken the Williamsonian argument might not seem that

\footnotetext{
${ }^{4}$ Cf. also Holmström and Milgrom (1991), and Holmström and Tirole (1991).
} 
surprising - see Artz and Brush (2000), and Garvey (1995). What is more striking is that the negative relationship between the level of specificity and vertical integration is present also in the static model, where no reputational forces are at work. ${ }^{5}$ In the static case, nonintegration always generates a larger joint surplus than integration when asset specificity is high. The reason is simple. When the value of the good in the alternative use is much smaller than its value within the relationship the outside option does not bind and hence does not affect the bargaining outcome. Giving ownership to the non-investing (downstream) party would then only undermine the investment incentives of the investing (upstream) party. When asset specificity is low, on the other hand, external trade becomes a tempting alternative and the upstream party will in such situations favor actions that improve the alternative-use value over actions that improve the value of internal trade. Integration can be valuable here to control incentives because through integration the downstream party can prohibit external trade.

More in line with basic TCE predictions, I show that under relational contracting: (i) if asset specificity is high, large uncertainty over the value of internal trade favors (relational) integration over (relational) nonintegration; and (ii) if asset specificity is low, high uncertainty over the value of external trade favors (relational) integration over (relational) nonintegration. Specificity, when coupled with enough uncertainty about the supply price (the price the downstream party should have to pay to secure the good under nonintegration), eventually leads to integration - this eliminates the supply price as a temptation to either party for any level of asset specificity.

The next section presents the model in detail. In the following sections I take up the discussion of the optimal governance structure and asset ownership under the alternative bargaining environment in which the parties have outside options. I begin with the static version of the model and then turn to relational contracts. Following Baker et al. (2002; BGM hereinafter), we will refer to these two governance structures as 'spot' and 'relational', and identify vertical integration with 'employment' and nonintegration with 'outsourcing'. Thus we will call 'spot outsourcing' the case in which the upstream party owns the asset

\footnotetext{
${ }^{5}$ This was not the case with the one asset-one investor version of Chiu's (1998) static model, which supports the basic TCE prediction that high specificity should lead to integration. See the discussion below.
} 
and no relational contract is feasible, and so on.

\section{The Basic Model}

Consider the following setup, drawn from BGM. Two parties are engaged in a vertical relationship and can trade at dates $t=0,1,2 \ldots$; for simplicity we will call them $U$ (for upstream) and $D$ (for downstream). Both parties live forever, are risk-neutral, share the same interest rate $r$ per period, and have sufficient wealth to purchase ownership rights whenever this is required. ${ }^{6}$ At each period $t, U$ uses an (infinitely-lived) asset to produce a good that is both valuable to $D$ (this value is $Q$ ) and in an alternative use (this value is $P$ ). The value of the good always falls to zero at the end of the period during which it was produced. The asset is specific in the sense that $Q>P$. Whoever owns the asset also owns the good.

We will consider a multitask environment: in each period the upstream party chooses a vector of actions $\mathbf{a} \in \Re_{+}^{n}$ that stochastically affects $Q$ and $P$. More specifically, $Q$ and $P$ can take high values (indexed by $\mathrm{H}$ ) or low values (indexed by L) satisfying $Q_{H}>Q_{L}>$ $P_{H}>P_{L}>0$, and the actions taken by the upstream party determine the probabilities of achieving either outcome: $Q_{H}\left(P_{H}\right)$ is realized with probability $q(\mathbf{a})(p(\mathbf{a})){ }^{7}$ These actions are of course costly to the agent: the cost of actions $\mathbf{a}$ is given by $c(\mathbf{a})$, which we will assume increasing and strictly convex. Assume further that $q(\mathbf{0})=p(\mathbf{0})=c(\mathbf{0})=0$ (taking no action is costless, but gives no chance of achieving high values), where $\mathbf{a}=\mathbf{0}$ can be interpreted as a normalization for some minimum level of effort exerted by $U$.

Actions are not observed by the downstream party. Outcomes (the realized values of $Q$ and $P$ ), on the other hand, are observable by both parties but nonverifiable (for instance, by a court). Therefore, contracts based on a, $Q$ or $P$ cannot be enforced by a third party. Under integration, $D$ can simply take the good without any payment to $U$ once production takes place. Under nonintegration, since $Q>P$ there will be bargaining over the ownership

\footnotetext{
${ }^{6}$ We thus abstract from financial considerations. On this, see Hansmann (1996). See also Aghion and Tirole (1994) for an application to R\&D where one party is cash constrained.

${ }^{7}$ Note that the crucial assumption here is that the asset is specific for every realization of $Q$ and $P$; hence the analysis can be generalized to any finite number of values, as in Baker et al. (2001), or to any joint distribution function that assigns positive probability only to events involving $Q>P$.
} 
of the good. ${ }^{8}$ This will involve $D$ paying $U$ a (bargained) price $\rho$ for the good. As we will discuss shortly, results and predictions depend on how $\rho$ is determined.

\section{Spot governance structures}

In this section we want to characterize equilibrium actions and payoffs under both spot governance structures available: $D$-ownership or employment, and $U$-ownership or outsourcing. In order to do so, we fix in turn the two choices in the first move of the game to integration (employment) and nonintegration (outsourcing), and study the continuation games according to the timing laid out in Figure 1. Since under nonintegration there is bargaining over the ownership of the good, we also introduce the proposed bargaining protocol at this point. Finally, we end the section by analyzing the optimal integration decision. ${ }^{9}$

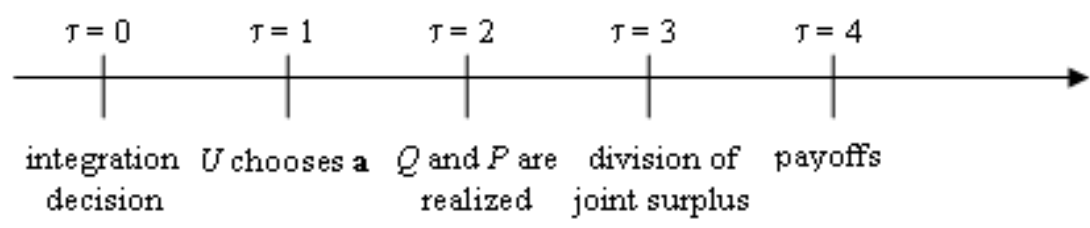

Figure 1: The timing of the game

\subsection{Spot employment}

We begin by studying the case of integration under spot governance, what we have labeled spot employment. The outcome is simple when the downstream party owns the asset: Since no contract (formal or relational) is available the downstream party can simply take the good

\footnotetext{
${ }^{8}$ Since $Q$ and $P$ are observed by both parties, bargaining takes place under complete information and the outcome is ex post efficient. For a model with bargaining with private information and ex post inefficiencies, see Matouschek (2004).

${ }^{9}$ We will not consider the case of joint ownership. Since under joint ownership the asset can be used only by consent, in our simple setting it would amount to assuming that outside options are zero for both parties, and results would be as in the case of high asset specificity (see below).
} 
and refuse to make any payment to the upstream party. In anticipation of this, the optimal choice for the upstream party is to take no costly action, i.e., to choose $\mathbf{a}=(0,0, \ldots, 0)$. Then the value of the good to the downstream party is $Q_{L}$ with probability 1. Let the superscript $S E$ denote spot employment. Payoffs are then $U^{S E}=0$ and $D^{S E}=Q_{L}$, and joint surplus is simply

$$
S^{S E}=U^{S E}+D^{S E}=Q_{L}
$$

Of course these values depend on neither the bargaining protocol nor the level of asset specificity. When no contract is feasible, then the only means by which to provide incentives for $U$ is to give her the ownership of the asset. Since under nonintegration there is bargaining over the price of the good, we turn to this matter before considering life under spot outsourcing.

\subsection{Bargaining rules}

Since $Q>P$, under nonintegration there is bargaining over the ownership of the good after production takes place. At this point, BGM follow the standard property rights theory (whether static or dynamic) and use the axiomatic Nash bargaining solution, a solution that assigns each party her disagreement payoff plus half of the surplus created. We can think of a situation where there is a spot market for the good in which $U$ continues to trade at price $P$ while bargaining with $D$. With this bargaining solution, however, BGM's results do not depend on the level of asset specificity, i.e., they all hold as soon as $Q-P$, the aggregate level of quasi-rents created by the investment, is positive - irrespective of how large that difference is. This is unfortunate, for it does not allow us to rigorously investigate the kind of Williamsonian assertions we are focusing on.

Consider instead a situation in which to sell the good to a different downstream party (or in a spot market) the upstream party must quit bargaining with the downstream party. For instance, looking for a new partner might be time-consuming, or require some marketing costs. By the time this is done, it may be too late for $D$ to wait further for another good to be produced. $P$ then constitutes an outside option in the sense of Binmore, Rubinstein, and Wolinsky (1986, p. 185). As is well known, when this outside option is always available each 
bargainer obtains half of the joint surplus, unless this gives one of them strictly less than her outside option (in which case she must receive the latter, the other party receiving what is left). This is what Binmore, Shaked and Sutton (1989) termed the "deal-me-out" rule, in which the outside options are used only as constraints on the range of validity of the Nash solution..$^{10}$

Under the deal-me-out rule, we have that the payoffs to $D$ and $U\left(s_{D}\right.$ and $\left.s_{U}\right)$ from bargaining are given by: ${ }^{11}$

$$
\left(s_{D}, s_{U}\right)= \begin{cases}\left(\frac{Q_{i}}{2}, \frac{Q_{i}}{2}\right) & \text { if } \frac{Q_{i}}{2}>P_{j} \\ \left(Q_{i}-P_{j}, P_{j}\right) & \text { if } \frac{Q_{i}}{2} \leq P_{j}\end{cases}
$$

Notice that since the downstream party's outside option is zero, it can never bind. As is clear from the expressions above (see also Proposition 6 in Binmore, Rubinstein and Wolinsky, 1986), U's outside option is relevant (it affects the equilibrium outcome) only if it constitutes a credible threat, i.e., if it binds. This alternative model of bargaining captures the very natural phenomenon where a party keeps matching the other party's outside offers as in the case of the employer-employee relationship - and has received experimental support (see Binmore, Shaked and Sutton, 1989). ${ }^{12}$ It is a natural way to model ex post bargaining in Williamsonian hold-up contexts. The advantage of this bargaining model is that it allows the level of asset specificity to affect the optimal allocation of property rights.

With outside-options bargaining, the bargained price $\rho$ of the good depends on realized asset specificity $A S_{i j} \equiv Q_{i}-P_{j}$ :

$$
\rho= \begin{cases}\frac{Q_{i}}{2} & \text { if } A S_{i j}>P_{j} \\ P_{j} & \text { otherwise }\end{cases}
$$

\footnotetext{
${ }^{10}$ Compare this to the standard Nash bargaining solution, in which $U$ 's option to put the good to its alternative use is simply taken as shifting the disagreement point from $(0,0)$ to $(0, P)$ in the Nash product. This solution assigns each party her disagreement payoff plus half of the surplus generated by the agreement, an outcome that has been termed 'split-the-difference' in the literature. Binmore, Rubinstein and Wolinsky (1986) discuss extensively the application of the Nash bargaining solution in economic modelling.

${ }^{11}$ In what follows, $Q$ and $P$ will make reference to the random variables, whereas $Q_{i}$ and $P_{j}$ will denote realizations of these variables.

${ }^{12}$ See also the discussion in Chiu (1998).
} 
The upstream party's outside option will not bind as long as $A S_{i j}>P_{j}$. Put differently, which price arises depends on whether the level of asset specificity is greater or less than a threshold given by the alternative-use value of the good.

\subsection{Spot outsourcing}

We now consider matters under nonintegration, i.e., when the upstream party owns the asset. Whatever the bargaining environment, $U$ will take the expected outcome of the process into account when choosing her actions. Denote $E[\rho]$ the expected price of the good. Let the superscript $S O$ stand for spot outsourcing. Then the payoff to the upstream party is given by

$$
U^{S O}=\max _{\mathbf{a}} E[\rho]-c(\mathbf{a})=E\left[\rho \mid \mathbf{a}=\mathbf{a}^{S O}\right]-c\left(\mathbf{a}^{S O}\right)
$$

whereas the downstream party's payoff is $D^{S O}=E\left[Q-\rho \mid \mathbf{a}=\mathbf{a}^{S O}\right]$, where $\mathbf{a}^{S O} \in \arg \max$ $E[\rho]-c(\mathbf{a})$. The total surplus of the relationship is then

$$
S^{S O}=U^{S O}+D^{S O}=E\left[Q \mid \mathbf{a}=\mathbf{a}^{S O}\right]-c\left(\mathbf{a}^{S O}\right)
$$

Note that the expression for $\rho$ depends on the realization of $A S$ (and hence on those of $Q$ and $P$ ). The upstream party, however, chooses a before $Q$ and $P$ are observed. Call the case in which $A S_{i j}>P_{j}$ a situation of (relatively) 'high asset specificity', and the case $A S_{i j}<P_{j}$ a situation of (relatively) 'low asset specificity'. For $U$ to know which bargaining environment will prevail (high or low specificity) when choosing a, we will assume that parameter values are such that we are always on one side of the threshold or the other - that is, we will make two mutually exclusive assumptions, namely,

$$
A^{h}: Q_{L}>2 P_{H} \quad \text { (high specificity) }
$$

and

$$
A^{l}: Q_{H}<2 P_{L} \quad \text { (low specificity) }
$$

and perform the analysis under each of those alternatively to see how results are modified. These assumptions allow us to focus on the two extreme cases in the most simple setting, and to isolate the effects of the degree of asset specificity on the integration decision. 
Under $A^{h}, U^{\prime}$ 's outside option will never bind whatever the realizations of $Q$ and $P$; i.e., we will always be in a situation of high specificity (hence we will index all variables by the superscript $h$ ). When the alternative assumption $A^{l}$ holds, the upstream party's outside option will always bind, and therefore low asset specificity (superscript $l$ ) will prevail. The bargained price of the good in each case will be given by

$$
\rho^{h}=\frac{Q_{i}}{2}
$$

and

$$
\rho^{l}=P_{j}
$$

Notice that here, contrary to BGM, even under nonintegration $P$ may play no role (specifically, when asset specificity is high).

\subsection{The integration decision}

The comparison between the two ownership structures is straightforward. Let $\Delta Q=Q_{H}-$ $Q_{L}$. Integration will be chosen as long as this maximizes the joint surplus:

$$
\begin{gathered}
S^{S E}>S^{S O} \\
\Longleftrightarrow q\left(\mathbf{a}^{S O}\right) \Delta Q<c\left(\mathbf{a}^{S O}\right) .
\end{gathered}
$$

Spot employment can only dominate spot outsourcing when providing incentives to the upstream party for taking costly actions reduces total surplus. This can easily be seen if we rewrite (3) as

$$
\left(q\left(\mathbf{a}^{S O}\right)-q(\mathbf{0})\right) \Delta Q<c\left(\mathbf{a}^{S O}\right)-c(\mathbf{0})
$$

Incentives will not be provided (by giving ownership to $U$ ) whenever the cost of extracting effort from the upstream party is larger than the benefit of doing so (i.e., achieving a higher outcome with a higher probability). This could happen, for instance, if in order to improve her bargaining position the upstream party takes actions to increase the alternative-use value of the good at the expense of the value to the downstream party.

To gain more insight into the optimality of each regime we will place more structure on the model. Following BGM, we will assume $U$ takes two actions that affect linearly the 
probabilities of obtaining high values, and that impose quadratic costs on her. Formally,

$$
\begin{aligned}
\mathbf{a} & =\left(a_{1}, a_{2}\right) \\
q(\mathbf{a}) & =q_{1} a_{1}+q_{2} a_{2} \\
p(\mathbf{a}) & =p_{1} a_{1}+p_{2} a_{2} \\
c(\mathbf{a}) & =\frac{1}{2} a_{1}^{2}+\frac{1}{2} a_{2}^{2}
\end{aligned}
$$

where $q_{1}, q_{2}, p_{1}, p_{2} \geq 0$ and $q_{1} p_{2} \neq q_{2} p_{1}$. It is now easy to show the following. (For ease of exposition the proofs and more formal statements of this and all other results will be relegated to the Appendix.)

\section{Proposition 1 Under spot governance:}

(i) If asset specificity is high, integration is always dominated by nonintegration.

(ii) If asset specificity is low, both a small variability in the value of the good to the downstream party and a large variability in the alternative-use value of the good favor integration over nonintegration.

In the static case, when asset specificity is high integration always yields a smaller joint surplus than nonintegration. A potential drawback with outsourcing is that improving the alternative-use value $P$ of the good may draw excessive attention from the upstream party. The upside of integration is that it eliminates $P$ as a temptation. When the outside option is not binding, however, $P$ is already irrelevant (i.e., it has no effect on the bargaining outcome), and integration loses most of its appeal: it would just mean giving the asset to the party who does not make relationship-specific investments, hence reducing the investment incentives of the upstream party.

Spot employment can only dominate spot outsourcing when asset specificity is low. In that case the upstream party's outside option is high ex post (i.e., it binds) with outsourcing, and therefore her ex ante incentives will be driven by the effects of actions on her outside option, rather than on the value of the good to the downstream party. The drawback with employment is that it may cause excessive hold-up: spot employment is associated with full hold-up of $U$ by $D$, and therefore generates zero ex ante incentives. Nonintegration provides incentives for costly actions, but in our multitasking setup these are driven by $\Delta P=P_{H}-P_{L}$, 
the return on investments on the alternative-use value of the good, when asset specificity is low (see the Appendix). A large variability in the alternative-use value of the good, that is, a large $\Delta P$, implies that incentives for the wrong actions are powerful, and hence integration becomes a superior governance structure by eliminating incentives altogether.

As shown in the Appendix, an increase in $\Delta Q$, the variability in the value of the good to the downstream party, does not affect actions when asset specificity is low. On the other hand, it increases the left-hand side of (3) above, thus making the optimality of integration less likely. Integration can only be the efficient governance mode when this variability is small enough, as Proposition 1(ii) remarks. ${ }^{13}$

Asset ownership always motivates $U$ here, as in Hart (1995), even with outside options. This has to be contrasted with De Meza and Lockwood (1998), who show that asset monotonicity of investment does not necessarily hold with outside options. In their setup, if giving ownership to the noninvestor makes her outside option bind, the investing party is made residual claimant of her investment, and thus has better investment incentives. Their mechanism does not work here, however: given our assumptions, D's outside option can never bind. This does not imply that the investor should always own the asset. On the contrary, Proposition 1 identifies circumstances in which it is optimal to give ownership to the noninvestor, and should be contrasted with Proposition 2 in Hart and Moore (1990, p. 1131), which says that whenever only one agent can invest, she should own the asset. Of course the key to our different predictions is multitasking. ${ }^{14}$

According to Proposition 1 there is a sense in which an increase in asset specificity leads to less integration: we can always find $\Delta P$ and $\Delta Q$ such that spot employment dominates spot outsourcing under low asset specificity, whereas going to a situation of high asset specificity would shift the efficient organizational form from integration to nonintegration. Moreover, given the first part of the proposition there is no way that an increase in specificity can change the efficient governance structure from outsourcing to employment.

The results in this section are influenced by the fact that the lack of a relational contract

\footnotetext{
${ }^{13}$ Another way to think of the results in part (ii) of Proposition 1 is that spot employment can dominate spot outsourcing only if there is overinvestment under nonintegration (i.e., if $\Delta P \gg \Delta Q$ ).

${ }^{14}$ See Cai (2003) for related results. Chiu (1998) identifies other circumstances in which ownership by the noninvesting party is the most efficient arrangement, even with unidimensional investments.
} 
precludes the use of bonuses to provide incentives; asset ownership is then the only remaining means. How these conclusions are affected when relational contracts are available will be the focus of the following section, where we analyze repeated-game versions of the model presented in section 2 .

\section{Governance under relational contracts}

Regardless of the ownership arrangement, the downstream party always wants the upstream party to take actions that increase $Q$. Ongoing interaction may provide an instrument for providing effective incentives which is not available in the static framework of section 3: the downstream party may be able to make a self-enforcing promise to pay a bonus whenever a high value is achieved. This kind of implicit arrangement constitutes the essence of a relational contract.

Note that a relational contract (if feasible) can never be worse than spot relationships. The parties can always play the static Nash equilibrium of the game, and this constitutes a subgame perfect Nash equilibrium in our supergame. In this section, we will thus see if and how asset ownership affects the feasibility of the superior relational contract. We will assume that the parties can trade at dates $t=0,1,2, \ldots$ according to the stage game depicted in figure 2 .

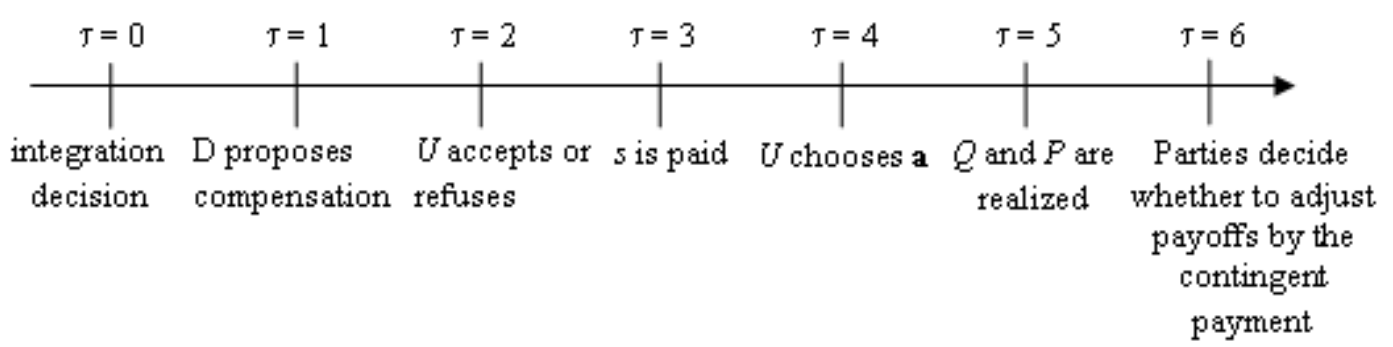

Figure 2: Timing with relational contracts

In general terms, compensation in a relational contract consists of a fixed payment (salary) $s_{t}$ and a contingent payment $b_{t}: \Phi \rightarrow \Re$, where $\Phi$ is the set of all possible re- 
alizations of the performance outcome observed by both parties, $\varphi_{t}=\left\{Q_{t}, P_{t}\right\}$. In principle, promised compensation can depend on the whole history of the relationship, and the relational contract can be quite messy; to characterize optimal relational contracts in this context, nevertheless, it suffices to look at stationary contracts, in which the downstream party promises the same compensation scheme in every period. ${ }^{15}$

Formally, total compensation in any period $t$ is given by $W_{t}=s+b\left(\varphi_{t}\right)$, and the discretionary payments in each period only depend on the performance outcome in the same period. Within our simple setting, the relational compensation contract can be best described as $\left(s,\left\{b_{i j}\right\}\right)=\left(s, b_{H H}, b_{H L}, b_{L H}, b_{L L}\right)$, where the salary $s$ is paid by the downstream party to the upstream party at the beginning of each period and $b_{i j}$ is supposed to be paid when $Q=Q_{i}$ and $P=P_{j}$, for $i, j=\mathrm{H}$, L. In analyzing self-enforcing relational contracts, we can concentrate on contracts that maximize the joint surplus of the relationship (subject to self-enforceability), since the fixed compensation in the initial period of the contract can be adjusted to redistribute surplus without affecting underlying incentives. ${ }^{16}$

If $U$ accepts the relational contract offered by $D$, her period payoff will be

$$
\begin{aligned}
U^{R}= & \max _{\mathbf{a}} s+b_{H H} q(\mathbf{a}) p(\mathbf{a})+b_{H L} q(\mathbf{a})(1-p(\mathbf{a}))+b_{L H}(1-q(\mathbf{a})) p(\mathbf{a})+ \\
& +b_{L L}(1-q(\mathbf{a}))(1-p(\mathbf{a}))-c(\mathbf{a})=E\left[s+b \mid \mathbf{a}=\mathbf{a}^{R}\right]-c\left(\mathbf{a}^{R}\right),
\end{aligned}
$$

where $\mathbf{a}^{R} \in \arg \max E[s+b]-c(\mathbf{a}) .{ }^{17}$ The downstream party's payoff is given by $D^{R}=$ $E\left[Q-s-b \mid \mathbf{a}=\mathbf{a}^{R}\right]$. The total surplus of the relationship is then

$$
S^{R}=U^{R}+D^{R}=E\left[Q \mid \mathbf{a}=\mathbf{a}^{R}\right]-c\left(\mathbf{a}^{R}\right) .
$$

A given relational contract will induce the same actions by the upstream party and thus produce the same surplus, irrespective of asset ownership, as long as the contract satisfies the corresponding feasibility constraint (which we analyze below). Since changing the bargaining environment changes the outcome of the process (the bargained price), this change in outcome may also change the parties' temptations to renege on the relational

\footnotetext{
${ }^{15}$ See Theorem 2 in Levin (2003, p. 840).

${ }^{16}$ See Theorem 1 in Levin (2003, p. 840).

${ }^{17}$ Results would not change if $U$ were to offer a contract to $D$.
} 
contract, and hence affect the feasibility of a contract. Therefore, a crucial part in what follows will be to compute the payoffs after reneging, what we do in the next subsections.

We will analyze trigger-strategy equilibria in which after a deviation from the relational compensation contract $\left(s,\left\{b_{i j}\right\}\right)$ the parties revert to the static equilibrium of the game forever - i.e., the party who did not renege refuses to enter into any new relational contract with the other party, and the relationship goes on under spot governance. Although generally trigger strategies are suboptimal (in the sense of Abreu, 1986, 1988), and not robust to ex post renegotiation, trembles and mistakes, they are simple and not that unrealistic. Since the main point of the paper is about bargaining rules, not strategies, I offer no further defense of this equilibrium concept here. The interested reader is referred to the papers by Blonski and Spagnolo (2003) and Kvaløy (2007) for a discussion of strategies within the setting of BGM.

We will also allow parties to negotiate to an efficient asset ownership arrangement after reneging. For example, under relational employment we will have spot employment when it is more efficient for $D$ to retain ownership of the asset $\left(S^{S E}>S^{S O}\right)$, and we will have spot outsourcing when it is more efficient for $U$ to buy it from $D$ at some price $\pi\left(S^{S O}>S^{S E}\right)-$ which she can always do given the sufficient wealth assumption.

\subsection{Reneging temptations under relational employment}

Let us begin the analysis of the parties' temptations to renege on the relational contract by looking at the case in which the downstream party owns the asset. In this situation of relational employment, $D$ can refuse to pay the promised bonus once $Q_{i}$ and $P_{j}$ are realized, and simply take the good without paying anything since she owns the asset. After reneging, and given our assumptions, she either retains ownership of the good and earns $D^{S E}$ in perpetuity, or sells the asset to $U$ at price $\pi$ and receives $D^{S O}$ in perpetuity. On the contrary, if the downstream party honors the contract, she pays $b_{i j}$ and continues with the relationship, thus making profit $D^{R E}$ each period in perpetuity. It follows that $D$ will stick 
to the terms of the relational contract whenever

$$
\begin{array}{ll}
-b_{i j}+\frac{1}{r} D^{R E} \geq \frac{1}{r} D^{S E} \quad & \text { if } S^{S E}>S^{S O}, \text { or } \\
-b_{i j}+\frac{1}{r} D^{R E} \geq \frac{1}{r} D^{S O}+\pi & \text { if } S^{S O}>S^{S E} .
\end{array}
$$

The upstream party can renege on the relational contract by refusing to accept a promised payment $b_{i j}$ (or to make a promised payment if $\left.b_{i j}<0\right)$. After that, she earns $U^{S E}$ per period for ever if she does not buy the asset, and she pays the price $\pi$ and obtains $U^{S O}$ in perpetuity if she buys the asset from $D$. On the other hand, if $U$ honors the contract, she receives $b_{i j}$ and continues with the relationship, thus making profit $U^{R E}$ each period in perpetuity. It follows that the upstream party will honor the contract as long as

$$
\begin{array}{ll}
b_{i j}+\frac{1}{r} U^{R E} \geq \frac{1}{r} U^{S E} \quad & \text { if } S^{S E}>S^{S O}, \text { or } \\
b_{i j}+\frac{1}{r} U^{R E} \geq \frac{1}{r} U^{S O}-\pi & \text { if } S^{S O}>S^{S E} .
\end{array}
$$

The present value of honoring the contract for $D(U)$ should exceed the present value of reneging for every value of $b_{i j}$, i.e., equations (5) and (6) ((7) and (8)) must hold for the maximum (minimum) value of the promised bonus. This is true both when $S^{S E}>S^{S O}$ and when $S^{S O}>S^{S E}$. We can combine these extreme versions of the reneging constraints into a single necessary and sufficient condition for a self-enforcing relational-employment contract (see BGM, p. 52, and Levin, 2003, Theorem 3, p. 842):

$$
\max b_{i j}-\min b_{i j} \leq \frac{1}{r}\left[S^{R E}-\max \left(S^{S O}, S^{S E}\right)\right]
$$

The feasibility constraint (9) says that the variation in contingent compensation has a limit given by the net future gains from the relationship. This condition is what Levin (2003) called the dynamic enforcement constraint. The left-hand side of the inequality is the maximum total temptation to renege on the relational-employment contract (i.e. the sum of both parties' temptations), whereas the right-hand side is the present value of net total surplus (i.e., continuation surplus $S^{R E}$, minus the best fallback if either party reneges, $\left.\max \left(S^{S O}, S^{S E}\right)\right)$. The efficient relational-employment contract maximizes the total surplus $S^{R E}$ in equation (4) subject to the dynamic enforcement constraint (9). ${ }^{18}$

\footnotetext{
${ }^{18}$ Note that the value of $S^{S O}$ will depend on the working assumption about the prevailing bargaining
} 


\subsection{Reneging temptations under relational outsourcing}

Let us now turn to the analysis of the feasibility of relational contracts under nonintegration. When $U$ owns the asset the comparison between the promised payment and the price that would result from bargaining under spot outsourcing determines each party's temptations to renege on the relational-outsourcing contract. In particular, if the promised bonus $b_{i j}$ exceeds the bargained price $\rho$ (where $\rho=\rho^{h}$ or $\rho^{l}$ depending on the level of asset specificity, as in equations (1) and (2)), the downstream party would be better off this period by reneging on the relational contract. Conversely, if $b_{i j}$ falls short of $\rho$, it is the upstream party who would be better off by reneging. Proceeding as with relational employment, we can show that a necessary and sufficient condition for the relational-outsourcing contract to be self-enforcing is

$$
\max \left(b_{i j}-\rho\right)-\min \left(b_{i j}-\rho\right) \leq \frac{1}{r}\left[S^{R O}-\max \left(S^{S O}, S^{S E}\right)\right]
$$

As in (9), the left-hand side is the maximum total reneging temptation, and the righthand side is the present value of the net total surplus. The efficient relational-outsourcing contract maximizes the total surplus $S^{R O}$ in equation (4) subject to this dynamic enforcement constraint. More specifically, (10) takes the form

$$
\max \left(b_{i j}-\frac{Q_{i}}{2}\right)-\min \left(b_{i j}-\frac{Q_{i}}{2}\right) \leq \frac{1}{r}\left[S^{R O}-\max \left(S_{h}^{S O}, S^{S E}\right)\right], \text { under } A^{h},
$$

or

$$
\max \left(b_{i j}-P_{j}\right)-\min \left(b_{i j}-P_{j}\right) \leq \frac{1}{r}\left[S^{R O}-\max \left(S_{l}^{S O}, S^{S E}\right)\right], \text { under } A^{l}
$$

i.e., when asset specificity is high and low. In BGM, "a key difference between relational contracts under outsourcing versus under employment is that the good's value in its alternative use, $P$, affects the reneging decision under relational outsourcing but not under relational employment". As can readily be seen from (11), with deal-me-out bargaining this is not true for high levels of asset specificity. Similarly, $Q$ (the value of the good to the downstream party) does not appear on the left-hand side of the reneging constraint (12).

environment (i.e., $A^{h}$ or $A^{l}$ ). We do not make this dependence explicit here in order to avoid additional subindices that would distract from the main point. 


\section{The boundaries of the firm}

Having now discussed the parties' temptations to renege on a relational contract under both governance structures, we can proceed to their comparison. By simple inspection of the feasibility constraints (9), (11), and (12), it becomes clear that for any level of asset specificity the parties' temptations to renege on a relational contract depend on the governance structure. Hence, asset ownership affects the feasibility of a given relational contract. ${ }^{19}$ This confirms the main insight in BGM (p. 56) and extends it to a different bargaining environment and to different levels of asset specificity.

To derive some further implications of the model we have just outlined, let us use the specific functional forms introduced in Section 3.4. Assume also that the bonus payments $b_{i j}$ take the specific form $b_{i j}=b_{i}+\beta_{j}(i, j=\mathrm{H}, \mathrm{L})$. Furthermore, let $\Delta b=b_{H}-b_{L}$ and $\Delta \beta=\beta_{H}-\beta_{L}$. The expected bonus can be written as $b_{L L}+q(\mathbf{a}) \Delta b+p(\mathbf{a}) \Delta \beta$, and thus we can interpret the assumed functional form as saying that the downstream party promises $b_{L}+\beta_{L}$ regardless of the outcomes and additional bonuses $\Delta b$ if $Q=Q_{H}$ (which occurs with probability $q(\mathbf{a})$ ) and $\Delta \beta$ if $P=P_{H}$ (which happens with probability $p(\mathbf{a})$ ), without any further payment (for example, if both $Q$ and $P$ achieve their highest values). For later reference, we will label $\Delta b$ ' $Q$-based incentives', and refer to $\Delta \beta$ as ' $P$-based incentives'.

Analyzing the special form taken now by the reneging constraints presented in Section 4 will allow us to derive some additional results. Under relational employment the selfenforcement constraint (9) writes as (see Appendix 1 in BGM)

$$
|\Delta b|+|\Delta \beta| \leq \frac{1}{r}\left[S^{R E}-\max \left(S_{k}^{S O}, S^{S E}\right)\right],
$$

where $k=h, l$ depending on the working assumption, $A^{h}$ or $A^{l}$. Recall that $\Delta Q=Q_{H}-Q_{L}$ and $\Delta P=P_{H}-P_{L}$. Under relational outsourcing with outside options, we can show (see the Appendix) that the necessary and sufficient conditions (11) and (12) for the relationaloutsourcing contract to be self-enforcing can be written as follows:

$$
\left|\Delta b-\frac{1}{2} \Delta Q\right|+|\Delta \beta| \leq \frac{1}{r}\left[S^{R O}-\max \left(S_{h}^{S O}, S^{S E}\right)\right], \text { under } A^{h},
$$

\footnotetext{
${ }^{19}$ Asset ownership is not the only means to affect reneging temptations. Multimarket contact (Bernheim and Whinston, 1990) and social relations (Spagnolo, 1999) may be relevant factors also, just to mention a couple.
} 
i.e., if asset specificity is high; and

$$
|\Delta b|+|\Delta \beta-\Delta P| \leq \frac{1}{r}\left[S^{R O}-\max \left(S_{l}^{S O}, S^{S E}\right)\right], \text { under } A^{l}
$$

i.e., if asset specificity is low.

We can now show how higher levels of asset specificity can make the optimality of nonintegration more likely, that is, how high levels of quasi-rents may provide a rationale for nonintegration.

Proposition 2 Under bargaining with outside options, the first best is easier (harder) to achieve with a relational-outsourcing contract than with relational employment when the degree of asset specificity is high (low).

The first best actions are those which maximize the joint surplus $E[Q]-c(\mathbf{a})$. It is not hard to guess (see the Appendix) that achieving the first-best outcome requires providing only $Q$-based incentives (and no bonuses based on $P$ ), that is, $\Delta b>0$ and $\Delta \beta=0$. Proposition 2 claims that these bonuses that deliver the first-best outcome generate the smallest (largest) temptation to renege on the relational contract under nonintegration when asset specificity is high (low). The presence of multitasking and outside options is once again key to understand this result, which might look counterintuitive at first (TCE) glance.

For given first-best bonuses, the reneging temptation of the downstream party is always lower under relational outsourcing because only the amount above the bargained price can be saved through defection, whereas under relational employment the full bonus can be saved. Nonintegration, however, creates a temptation for the upstream party when the realized value of internal trade is low, because she does not receive the bonus $\Delta b$ in this case, but can obtain something through bargaining by defecting. When asset specificity is high, U's increased reneging temptation is more than compensated by the reduction in $D$ 's defection incentives: high specificity means that the outside option does not bind and that external trade is not a tempting option; $P$ becomes irrelevant and $U$ 's attention is not diverted by the value of external trade. Hence the total temptation to renege on the first-best, relationaloutsourcing contract is lower when the parties remain nonintegrated in situations of high asset specificity. 
When specificity is low, on the other hand, the realization of $P$ matters: the upstream party has incentives to improve the alternative-use value in order to improve her bargaining position, even though achieving first best calls for zero incentives on $P$. The upside of integration is that it eliminates external trade as an option. It is true that the downstream party has a larger temptation to renege under integration, but this is overcome by the elimination of $U$ 's reneging temptation, so that the total temptation to renege on the first-best, relational-employment contract is lower under integration when asset specificity is low.

In a sense the goals of both parties are best aligned in the case of a nonbinding outside option, but they are most conflictive when the outside option binds. As we have already discussed, the outside option does not bind when asset specificity is high, and the realization of $P$ is thus irrelevant under both ownership regimes: the first-best, $P$-based bonus is zero and the bargained price does not depend on the alternative-use value. The upstream party may be more committed to enhancing the value of the relationship (that is, $Q$ ) when she has few alternative opportunities in case the relationship breaks up (when $P$ is low relative to $Q$, and thus the outside option does not bind). ${ }^{20}$

Proposition 2 is the main result of the paper: it focuses on the level of asset specificity and gives interestingly the opposite prediction to transaction cost economics - especially if combined with Proposition 1, which showed that, with one-shot relationships, integration could only be efficient in a situation of low asset specificity. These results offer theoretical support to the casual observation that in "[m]any of the hybrid organizations that are emerging, [... high degrees of frequency and mutual dependency seem to support, rather than hinder, ongoing cooperation across firm boundaries" (Holmström and Roberts, 1998, p. 92). The most cited example of this sort concerns the relations between Japanese car manufacturers and their suppliers (Cusumano, 1985; Dyer, 1996; Womack et al., 1990). Holmström and Roberts (1998) go so far as to argue that the "Japanese [procurement and subcontracting] pattern is directly at odds with transaction cost theory" (see also the findings in Dyer, 1996, p. 650). Consider in addition the evidence in Anderson et al. (2000) who document that, under relational contracting, "factors that previous studies found to favor insourcing now favor outsourcing" in U.S. automakers - most importantly, that the greater the complexity

\footnotetext{
${ }^{20}$ See De Meza and Lockwood (1998) for a related claim.
} 
of the product (a proxy for specificity), the greater the likelihood of outsourcing. ${ }^{21}$

The following results are more in line with Williamsonian predictions.

\section{Proposition 3 Under relational contracting:}

(i) If asset specificity is high, a large variability in the value of the good to the downstream party favors (relational) integration over (relational) nonintegration.

(ii) If asset specificity is low, a large variability in the alternative-use value of the good favors (relational) integration over (relational) nonintegration.

When the upstream party owns the asset, she has the right to put the good to an alternative use, and hence the bargained price of the good $\rho$ has a clear bearing on the temptations to renege on a given relational-outsourcing contract: if the promised bonus falls short of $\rho$ the upstream party would be better-off this period by defecting; if the negotiated price is less than the promised payment, it is the downstream party who would have an incentive to renege. In a situation of high asset specificity, $\rho=Q_{i} / 2$ and large uncertainty on $Q$ implies a large variability of the price the downstream party would have to pay to secure the good under nonintegration. Similarly, when asset specificity is low, $\rho=P_{j}$ and uncertainty on $P$ translates one for one into uncertainty on the supply price.

Now notice that equations (11') and (12') suggest that (i) too large a variation in the value of the good to $D$ under high specificity, and (ii) too large a variation in the alternativeuse value under low specificity, would render relational outsourcing infeasible because the total temptation to renege would be too high. This is not the case with integration: the feasibility constraint on relational-employment contracts $\left(9^{\prime}\right)$ does not depend on $\Delta Q$ nor $\Delta P$. Proposition 3 confirms this intuition. The result has a TCE flavor: Specificity, when coupled with enough uncertainty (about the supply price $\rho$ ), eventually leads to (relational) integration - vertical integration eliminates the supply price as a temptation to either party for any level of asset specificity. ${ }^{22}$

When coupled with Proposition 1(ii), Proposition 3(ii) has a straightforward implication:

\footnotetext{
${ }^{21} \mathrm{Mol}$ (2005) finds a similar pattern in the Dutch manufacturing sector.

${ }^{22}$ The availability of relational contracts implicitly assumes that $r$ is low enough.
} 
Corollary 1 Ownership by the downstream party is efficient when asset specificity is low and uncertainty on the alternative-use value of the good is high.

Uncertainty on $P$ favors integration when asset specificity is low: either spot employment or relational employment will generate the largest joint surplus. The corollary thus provides a qualification of Result 1 in BGM (p. 76), which says that vertical integration is the efficient governance structure when $\Delta P$ is large, by stating the condition under which it is more likely to be true (namely, low asset specificity).

\section{Concluding remarks}

The main economic message of this paper is that in a world where outside options matter and investments are multidimensional, high levels of asset specificity can foster nonintegration. Thus, the paper provides a rationale for the pattern of new organizational forms that we are seeing, which are "characterized by high degrees of uncertainty, frequency and asset specificity", and yet "do not lead to integration" (Holmström and Roberts, 1998, p. 92) a pattern that has proved hard to explain with traditional transaction cost economics. As in Gibbons (2005, p. 207), "parties choose to transact in firms precisely when transacting in a market would produce misdirected incentives"; here, it is a low level of asset specificity that provides the most misdirected incentives (because the outside option of external trade becomes so tempting), thus making a stronger case for nonintegration when specificity is high.

Holmström and Roberts (1998, p. 92) contend that "[t]he property rights approach, with its emphasis on incentives driven by ownership, may be a good starting point for investigating these new hybrid structures". As is well known, however, marginal, not total, returns determine investments in the property rights theory of the firm. For this reason the level of asset specificity has no bearing on the make-or-buy decision. ${ }^{23}$ In this paper, I provide a simple and straightforward way of incorporating these different levels of asset specificity in a dynamic, relational contracting model of the firm in the spirit of the property rights approach, and show that these levels matter even in the static version of the model. The role

\footnotetext{
${ }^{23}$ See, for instance, Holmström (1999) and Whinston (2003).
} 
of the level of specificity emerges naturally once I drop the standard Nash bargaining solution widely used in the property rights theory, and consider instead an alternative situation in which to take up an outside option one party must quit bargaining with the other party.

To the best of my knowledge, I am the first to explore the effects of outside options bargaining in dynamic property rights models. ${ }^{24} \mathrm{I}$ am not, nevertheless, the first to show that the level of asset specificity can matter in the property rights approach. Chiu (1998) and De Meza and Lockwood (1998) have already introduced bargaining with outside options in static property rights models, and have shown that some of their basic lessons can be reversed. Even though they do not emphasize it explicitly, it is not hard to see that under the outside option principle the level of specificity matters for the optimal ownership structure in their work.

The way in which it matters, however, is different. Given their assumptions, for any ownership structure, equilibrium investment levels are less than their first-best levels, which implies that the optimal ownership structure is the one that maximizes investment. The level of asset specificity determines whether this is achieved by giving or taking away ownership from the investor. Taking ownership away can foster investment if it makes the investor residual claimant, which happens when the noninvestor's outside option binds. In my paper the noninvesting party's outside option never binds. With multidimensional investments the level of asset specificity directs the allocation of investment efforts through the investor's outside option, and muted incentives can be optimal. Besides, Chiu (1998) and De Meza and Lockwood (1998) do not provide clean arguments for which way the relationship between specificity and integration goes and why, and it is not hard to see that in the one asset-one investor version of Chiu's model high levels of specificity favor integration, as in TCE.

Here I have moved from a static to a relational world, which is arguably a better description of the real world (see BGM), to analyze the role of the level of asset specificity. In contemporaneous work, Kvaløy (2007) also makes the level of asset specificity matter in a BGM-like framework and again questions the central hypothesis of transaction cost economics about specificity and integration. He achieves this through a different approach,

\footnotetext{
${ }^{24}$ Other papers that investigate alternative bargaining protocols in different dynamic hold-up settings are Che and Sakovics (2007), and Evans (2008).
} 
however, as his work maintains BGM's 50:50 Nash bargaining solution, and assumes instead that the parties refuse to trade with each other in the punishment phase (similar to Klein and Leffler, 1981).

Throughout the analysis, I have taken the level of asset specificity to be exogenous. While this is in line with virtually every empirical study of the TCE, asset specificity is often a choice variable, and endogenizing it would be an interesting avenue for future research. Ellman (2006) discusses why firms would intentionally choose to increase specificity, and though the issue of the boundaries of the firm does not appear formally in his model, the author discusses how organizational design (integration) could be chosen to foster this specificity. In my paper, joint ownership (e.g. a joint venture) can be used when asset specificity is low to replicate the results under high specificity without integrating. ${ }^{25}$ This choice can make the outside option of the investor non-binding (thus providing him with better investment incentives) and increase the parties' joint surplus. ${ }^{26}$

\section{Appendix}

\section{A.1 Proof of inequalities (11') and (12')}

This proof parallels that in Appendix 1 in BGM. Let $Z=b_{L}+\beta_{L}-\frac{1}{2} Q_{L}$ and $W=b_{L}+\beta_{L}-P_{L}$. Under $A^{h}$ the left hand side of the dynamic enforcement constraint (10), i.e., the reneging temptation, is $\max \left(b_{i j}-\frac{Q_{i}}{2}\right)-\min \left(b_{i j}-\frac{Q_{i}}{2}\right)$. For every pair of realizations of $Q$ and $P$, we have

$$
\begin{aligned}
& b_{H H}-\frac{1}{2} Q_{H}=b_{H}+\beta_{H}-\frac{1}{2} Q_{H}=\Delta b-\frac{1}{2} \Delta Q+\Delta \beta+Z \\
& b_{H L}-\frac{1}{2} Q_{H}=b_{H}+\beta_{L}-\frac{1}{2} Q_{H}=\Delta b-\frac{1}{2} \Delta Q+Z \\
& b_{L H}-\frac{1}{2} Q_{L}=b_{L}+\beta_{H}-\frac{1}{2} Q_{L}=\Delta \beta+Z \\
& b_{L L}-\frac{1}{2} Q_{L}=b_{L}+\beta_{L}-\frac{1}{2} Q_{L}=Z
\end{aligned}
$$

${ }^{25}$ See also Rajan and Zingales (1998).

${ }^{26}$ Halonen (2002) argues that mutual dependency through joint ownership (by removing the investor's outside option) can make the first best easier to achieve when the parties are very important to each other, which is reminiscent of my Proposition 2. 
Let $\max (\bullet)$ and $\min (\bullet)$ denote the maximum and minimum of the expressions above. There are four cases to consider:

1. $\Delta b-\frac{1}{2} \Delta Q>0, \Delta \beta>0$. Then, $\max (\bullet)=(\mathrm{HH})$ and $\min (\bullet)=(\mathrm{LL})$, and the reneging temptation is $\Delta b-\frac{1}{2} \Delta Q+\Delta \beta$.

2. $\Delta b-\frac{1}{2} \Delta Q>0, \Delta \beta<0$. Then, $\max (\bullet)=(\mathrm{HL})$ and $\min (\bullet)=(\mathrm{LH})$, and the reneging temptation is $\Delta b-\frac{1}{2} \Delta Q-\Delta \beta$.

3. $\Delta b-\frac{1}{2} \Delta Q<0, \Delta \beta<0$. Then, $\max (\bullet)=(\mathrm{LL})$ and $\min (\bullet)=(\mathrm{HH})$, and the reneging temptation is $-\left(\Delta b-\frac{1}{2} \Delta Q\right)-\Delta \beta$.

4. $\Delta b-\frac{1}{2} \Delta Q<0, \Delta \beta>0$. Then, $\max (\bullet)=(\mathrm{LH})$ and $\min (\bullet)=(\mathrm{HL})$, and the reneging temptation is $-\left(\Delta b-\frac{1}{2} \Delta Q\right)+\Delta \beta$.

These four cases can be subsumed in a single expression for the reneging temptation, $\left|\Delta b-\frac{1}{2} \Delta Q\right|+|\Delta \beta|$, which yields (11'). When $A^{l}$ holds the left hand side of $(10)$ is $\max \left(b_{i j}-P_{j}\right)-$ $\min \left(b_{i j}-P_{j}\right)$. For every pair of realizations of $Q$ and $P$, we now have

$(\mathrm{HH}) \quad b_{H H}-P_{H}=b_{H}+\beta_{H}-P_{H}=\Delta b+\Delta \beta-\Delta P+W$

(HL) $\quad b_{H L}-P_{L}=b_{H}+\beta_{L}-P_{L}=\Delta b+W$

$$
\begin{aligned}
& b_{L H}-P_{H}=b_{L}+\beta_{H}-P_{H}=\Delta \beta-\Delta P+W \\
& b_{L L}-P_{L}=b_{L}+\beta_{L}-P_{L}=W
\end{aligned}
$$

We can now proceed as in the high specificity case by replacing $\Delta b-\frac{1}{2} \Delta Q$ by $\Delta b$ and $\Delta \beta$ by $\Delta \beta-\Delta P$, to obtain a single expression for the reneging temptation, $|\Delta b|+|\Delta \beta-\Delta P|$, which yields (12') and completes the proof.

\section{A.2 Proof of Proposition 1}

Let $\Delta Q=Q_{H}-Q_{L}$ and $\Delta P=P_{H}-P_{L}$. The parties' payoffs and the total surplus in each situation can be written as:

$$
\begin{aligned}
U_{h}^{S O} & =\frac{1}{2}\left(Q_{L}+q\left(\mathbf{a}^{S O, h}\right) \Delta Q\right)-c\left(\mathbf{a}^{S O, h}\right) \\
D_{h}^{S O} & =\frac{1}{2}\left(Q_{L}+q\left(\mathbf{a}^{S O, h}\right) \Delta Q\right) \\
S_{h}^{S O} & =Q_{L}+q\left(\mathbf{a}^{S O, h}\right) \Delta Q-c\left(\mathbf{a}^{S O, h}\right)
\end{aligned}
$$


in a situation of high specificity (i.e., under $A^{h}$ ), and

$$
\begin{aligned}
U_{l}^{S O} & =P_{L}+p\left(\mathbf{a}^{S O, l}\right) \Delta P-c\left(\mathbf{a}^{S O, l}\right) \\
D_{l}^{S O} & =Q_{L}+q\left(\mathbf{a}^{S O, l}\right) \Delta Q-\left(P_{L}+p\left(\mathbf{a}^{S O, l}\right) \Delta P\right) \\
S_{l}^{S O} & =Q_{L}+q\left(\mathbf{a}^{S O, l}\right) \Delta Q-c\left(\mathbf{a}^{S O, l}\right)
\end{aligned}
$$

in the case of low specificity (i.e., under $A^{l}$ ). The optimal actions taken by the upstream party under spot outsourcing are:

$$
\begin{aligned}
& a_{1}^{S O}= \begin{cases}\frac{1}{2} q_{1} \Delta Q & \text { under } A^{h} \\
p_{1} \Delta P & \text { under } A^{l}\end{cases} \\
& a_{2}^{S O}= \begin{cases}\frac{1}{2} q_{2} \Delta Q & \text { under } A^{h} \\
p_{2} \Delta P & \text { under } A^{l}\end{cases}
\end{aligned}
$$

The joint surpluses above can thus be written as

$$
S_{h}^{S O}=Q_{L}+q\left(\mathbf{a}_{h}^{S O}\right) \Delta Q-c\left(\mathbf{a}_{h}^{S O}\right)=Q_{L}+\frac{3}{8}\left(q_{1}^{2}+q_{2}^{2}\right) \Delta Q^{2}
$$

and

$$
\begin{aligned}
S_{l}^{S O} & =Q_{L}+q\left(\mathbf{a}_{l}^{S O}\right) \Delta Q-c\left(\mathbf{a}_{l}^{S O}\right) \\
& =Q_{L}+\left(q_{1} p_{1}+q_{2} p_{2}\right) \Delta Q \Delta P-\frac{1}{2}\left(p_{1}^{2}+p_{2}^{2}\right) \Delta P^{2}
\end{aligned}
$$

As in Section 3, $a_{1}^{S E}=a_{2}^{S E}=0$ and $S^{S E}=Q_{L}$.

Formally, what we need to show to prove the first part of the proposition is that, for given values of $q_{1}, p_{1}, q_{2}, p_{2}$, if $A^{h}$ holds then $S^{S E}<S_{h}^{S O}$ for all $\Delta P$ and all $\Delta Q$. This follows trivially from the comparison of equation (A1) and $S^{S E}=Q_{L}$. To prove the second part of the proposition is tantamount to proving that, for given values of $q_{1}, p_{1}, q_{2}, p_{2}$, if $A^{l}$ holds then:

- there exists $\Delta P_{l}$ such that for all $\Delta P>\Delta P_{l}$ we have $S^{S E}>S_{l}^{S O}$, and

- there exists $\Delta Q_{l}$ such that if $\Delta Q>\Delta Q_{l}$ then $S_{l}^{S O}>S^{S E}$. 
If $A^{l}$ holds and $\Delta P \in\left(0, P_{L}\right),{ }^{27}$ by direct comparison of $S^{S E}$ and $S_{l}^{S O}$ in equation (A2), $S^{S E}>S_{l}^{S O}$ if and only if $\Delta P>\Delta P_{l} \equiv 2 \frac{q_{1} p_{1}+q_{2} p_{2}}{p_{1}^{2}+p_{2}^{2}} \Delta Q$, which proves the first point. Next consider the case of $\Delta Q$. Under $A^{l}$ the difference $S_{l}^{S O}-S^{S E}$ is increasing and linear in $\Delta Q$. Hence it will be positive for any $\Delta Q>\Delta Q_{l} \equiv \frac{\left(p_{1}^{2}+p_{2}^{2}\right) \Delta P}{2\left(q_{1} p_{1}+q_{2} p_{2}\right)}$ (as long as $\Delta Q<2 P_{L}-Q_{L}$ to satisfy $\left.A^{l}\right)$.

\section{A.3 Proof of Proposition 2}

The first best actions are those which maximize the joint surplus $E[Q]-c(\mathbf{a})$. Under the assumed functional forms these are the solution to

$$
\max _{a_{1}, a_{2}} Q_{L}+\left(q_{1} a_{1}+q_{2} a_{2}\right) \Delta Q-\frac{1}{2} a_{1}^{2}-\frac{1}{2} a_{2}^{2}
$$

Therefore,

$$
\begin{aligned}
a_{1}^{F B} & =q_{1} \Delta Q \\
a_{2}^{F B} & =q_{2} \Delta Q \\
S^{F B} & =Q_{L}+\frac{1}{2}\left(q_{1}^{2}+q_{2}^{2}\right) \Delta Q^{2} .
\end{aligned}
$$

Under a relational contract the upstream party chooses actions to maximize

$$
\left(s+b_{L}+\beta_{L}\right)+\left(q_{1} a_{1}+q_{2} a_{2}\right) \Delta b+\left(p_{1} a_{1}+p_{2} a_{2}\right) \Delta \beta-\frac{1}{2} a_{1}^{2}-\frac{1}{2} a_{2}^{2} .
$$

Her optimal choices are given by

$$
\begin{aligned}
& a_{1}^{R}=q_{1} \Delta b+p_{1} \Delta \beta, \\
& a_{2}^{R}=q_{2} \Delta b+p_{2} \Delta \beta .
\end{aligned}
$$

Clearly, we can only have the first best outcome under a relational contract if $\Delta b=\Delta Q>0$ and $\Delta \beta=0$, as long as the relevant feasibility constraint is satisfied by this particular relational compensation contract, namely

- $\Delta Q \leq \frac{1}{r}\left[S^{F B}-\max \left(S_{k}^{S O}, S^{S E}\right)\right], k=h, l$, under relational employment;

\footnotetext{
${ }^{27}$ The upper bound on $\Delta P$ guarantees that assumption $A^{l}$ is not violated.
} 
- $\frac{1}{2} \Delta Q \leq \frac{1}{r}\left[S^{F B}-\max \left(S_{h}^{S O}, S^{S E}\right)\right]$, under relational outsourcing and $A^{h}$; and

- $\Delta Q+\Delta P \leq \frac{1}{r}\left[S^{F B}-\max \left(S_{l}^{S O}, S^{S E}\right)\right]$, under relational outsourcing and $A^{l}$.

The proof follows from direct inspection of these inequalities above.

\section{A.4 Proof of Proposition 3}

To prove the first part of this result, we need to show that relational outsourcing becomes impossible for sufficiently large $\Delta Q$ when asset specificity is high. Formally, for given $q_{1}, p_{1}, q_{2}, p_{2}, \Delta P$, if $A^{h}$ holds then there exists $\Delta Q_{h}^{*}$ such that for all $\Delta Q>\Delta Q_{h}^{*}$, relational outsourcing is impossible - i.e., condition (11') fails. We will proceed in two steps to prove this:

Step 1. Too strong an incentive based on the value of the good to the downstream party makes relational outsourcing inferior to spot outsourcing, i.e., given $q_{1}, p_{1}, q_{2}, p_{2}, \Delta P$, there exists $\Delta b^{\prime}$ such that, for any $\Delta \beta$, if $\Delta b>\Delta b^{\prime}$ then $S^{R O}-S_{h}^{S O}<0\left(S_{h}^{S O}\right.$ stands for the joint surplus under spot outsourcing when specificity is high, and $S^{R O}$ for the surplus under relational outsourcing). The difference between $S^{R O}$ and $S_{h}^{S O}$, seen as a function of $\Delta b$, is a concave function. Hence, it will be negative for sufficiently large $\Delta b$, i.e. for $\Delta b>\Delta b^{\prime}$, where $\Delta b^{\prime}$ is the largest root of $S^{R O}-S_{h}^{S O}=\left(q_{1}^{2}+q_{2}^{2}\right)\left[\left(\Delta Q-\frac{1}{2} \Delta b\right) \Delta b-\frac{3}{8} \Delta Q^{2}\right]+$ $\left(q_{1} p_{1}+q_{2} p_{2}\right)(\Delta Q-\Delta b) \Delta \beta-\frac{1}{2}\left(p_{1}^{2}+p_{2}^{2}\right) \Delta \beta^{2}=0$.

Step 2. Choose $\Delta Q_{h}^{*}$ such that $\frac{1}{2} \Delta Q_{h}^{*}>\Delta b^{\prime}+\frac{1}{r}\left[S^{F B}-S_{h}^{S O}\right]$, where $S^{F B} \equiv \max E[Q]-$ $c$ (a) stands for first-best surplus. If $\Delta b>\Delta b^{\prime}$ we have from step 1 that $S^{R O}-S_{h}^{S O}<0$. Hence $S^{R O}-\max \left(S_{h}^{S O}, S^{S E}\right)<0$, and the necessary and sufficient condition for any relationaloutsourcing contract to be self-enforcing fails (since the left-hand side is always positive, and we have shown that the right-hand side is negative). If $\Delta b \leq \Delta b^{\prime}$, on the other hand, we have that $\frac{1}{2} \Delta Q_{h}^{*}>\Delta b$, so the first term on the left-hand side of the feasibility constraint (11') is at least $\frac{1}{2} \Delta Q_{h}^{*}-\Delta b \geq \frac{1}{2} \Delta Q_{h}^{*}-\Delta b^{\prime}>\frac{1}{r}\left[S^{F B}-S_{h}^{S O}\right] \geq \frac{1}{r}\left[S^{R O}-S_{h}^{S O}\right] \geq$ $\frac{1}{r}\left[S^{R O}-\max \left(S_{h}^{S O}, S^{S E}\right)\right]$, so once again the necessary and sufficient condition fails. Therefore, we have that too large a variation in the value to the downstream party makes relational outsourcing infeasible. 
To prove the second part of the proposition, it suffices to show that relational outsourcing is not feasible when asset specificity is low and $\Delta P$ is large enough. Formally, for given values of $q_{1}, p_{1}, q_{2}, p_{2}, r, \Delta Q$, if $A^{l}$ holds and $\Delta P \in\left(0, P_{L}\right),{ }^{28}$ then there exists $\Delta P_{l}^{\prime}$ such that for all $\Delta P>\Delta P_{l}^{\prime}$ the feasibility constraint (12') cannot be satisfied. Once again, we proceed in steps to prove this:

Step 1. From Lemma 2 in BGM (p. 76) we know that too strong an incentive based on the alternative-use value makes relational outsourcing inferior to spot employment, i.e., given $q_{1}, p_{1}, q_{2}, p_{2}, \Delta Q$ there exists $\Delta \beta^{\prime}$ such that, for any $\Delta b$, if $\Delta \beta>\Delta \beta^{\prime}$ then $S^{R O}-S^{S E}<0$. This result does not depend on the assumed bargaining scenario (see BGM for a proof).

Step 2. Choose $\Delta P_{l}^{\prime}$ such that $\Delta P_{l}^{\prime}>\Delta \beta^{\prime}+\frac{1}{r}\left[S^{F B}-S^{S E}\right]$, where $S^{F B} \equiv \max E[Q]-$ $c$ (a) stands for first-best surplus. If $\Delta \beta>\Delta \beta^{\prime}$ we have $S^{R O}-S^{S E}<0$ from step 1. Then $S^{R O}-\max \left(S_{l}^{S O}, S^{S E}\right)<0$, and the necessary and sufficient condition for the relationaloutsourcing contract to be self-enforcing, i.e., equation (12'), fails. If $\Delta \beta \leq \Delta \beta^{\prime}$, on the other hand, we have that $\Delta P_{l}^{\prime}>\Delta \beta$, so the second term on the left-hand side of the feasibility constraint (12') is at least $\Delta P_{l}^{\prime}-\Delta \beta \geq \Delta P_{l}^{\prime}-\Delta \beta^{\prime}>\frac{1}{r}\left[S^{F B}-S^{S E}\right] \geq \frac{1}{r}\left[S^{R O}-S^{S E}\right] \geq$ $\frac{1}{r}\left[S^{R O}-\max \left(S_{l}^{S O}, S^{S E}\right)\right]$, so once again the necessary and sufficient condition fails. Therefore, we have that too large a variation in the alternative-use value makes relational outsourcing infeasible.

\section{A.5 Proof of Corollary 1}

Formally, we want to show that, for given values of $q_{1}, p_{1}, q_{2}, p_{2}, r, \Delta Q$, if $A^{l}$ holds and $\Delta P \in\left(0, P_{L}\right)$ then there exists $\Delta P_{l}^{*}$ such that for all $\Delta P>\Delta P_{l}^{*}, D$-ownership is more efficient than $U$-ownership. From Proposition 1 we know that there exists $\Delta P_{l}$ such that if $\Delta P>\Delta P_{l}$ then $S^{S E}>S_{l}^{S O}$, i.e., spot outsourcing is not efficient. From Proposition 3 we have that, for any $\Delta P>\Delta P_{l}^{\prime}$, relational outsourcing is not feasible. To complete the proof, set $\Delta P_{l}^{*}=\max \left\{\Delta P_{l}, \Delta P_{l}^{\prime}\right\}$.

\footnotetext{
${ }^{28}$ The upper bound on $\Delta P$ guarantees once again that assumption $A^{l}$ is not violated.
} 


\section{References}

Abreu, D. (1986). 'Extremal equilibria of oligopolistic supergames', Journal of Economic Theory, vol. 39(1) (June), pp. 191-225.

Abreu, D. (1988). 'On the theory of infinitely repeated games with discounting', Econometrica, vol. 56(2) (March), pp. 383-96.

Acemoglu, D., Aghion, P., Griffith, R. and Zilibotti, F. (2007). 'Vertical integration and technology: theory and evidence', Working Paper No. 342, Institute for Empirical Research in Economics, University of Zurich, December.

Aghion, P. and Tirole, J. (1994). 'The management of innovation', The Quarterly Journal of Economics, vol. 109(4) (November), pp. 1185-209.

Anderson, S.W., Glenn, D. and Sedatole, K.L. (2000). 'Sourcing parts of complex products: evidence on transactions costs, high-powered incentives and ex-post opportunism', Accounting, Organizations and Society, vol. 25(8) (November), pp. 723-49.

Artz, K.W. and Brush, T.H. (2000). 'Asset specificity, uncertainty and relational norms: an examination of coordination costs in collaborative strategic alliances', Journal of Economic Behavior \& Organization, vol. 41(4) (April), pp. 337-62.

Baker, G., Gibbons, R. and Murphy, K.J. (2001). 'Bringing the market inside the firm?', The American Economic Review, vol. 91(2) (May), pp. 212-8.

Baker, G., Gibbons, R. and Murphy, K.J. (2002). 'Relational contracts and the theory of the firm', The Quarterly Journal of Economics, vol. 117(1) (February), pp. 39-84.

Bernheim, B.D. and Whinston, M.D. (1990). 'Multimarket contact and collusive behavior', Rand Journal of Economics, vol. 21(1) (Spring), pp. 1-26.

Binmore, K., Rubinstein, A. and Wolinsky, A. (1986). 'The Nash bargaining solution in economic modelling', Rand Journal of Economics, vol. 17(2) (Summer), pp. 176-88.

Binmore, K., Shaked, A. and Sutton, J. (1989). 'An outside option experiment', The Quarterly Journal of Economics, vol. 104(4) (November), pp. 753-70.

Blonski, M. and Spagnolo, G. (2003). 'Relational contracts and property rights', unpublished manuscript, University of Mannheim and Johann Wolfgang Goethe University.

Cai, H. (2003). 'A theory of joint asset ownership', Rand Journal of Economics, vol. 34(1) (Spring): 63-77.

Carter, R. and Hodgson, G.M. (2006). 'The impact of empirical tests of transaction cost economics on the debate on the nature of the firm', Strategic Management Journal, vol. 27(5) (May), pp. 461-76.

Che, Y.-K. and Sakovics, J. (2007). 'Contractual remedies to the hold-up problem: a dynamic perspective', American Law 85 Economics Association Annual Meetings, paper 14, bepress Legal Repository.

Chiu, Y.S. (1998). 'Noncooperative bargaining, hostages, and optimal asset ownership', The American 
Economic Review, vol. 88(4) (September), pp. 882-901.

Cusumano, M. (1985). The Japanese Automobile Industry: Technology and Management at Nissan and Toyota, Cambridge, MA: Harvard University - The Council on East Asian Studies.

David, R.J. and Han, S.-K. (2004). 'A systematic assessment of the empirical support for transaction cost economics', Strategic Management Journal, vol. 25(1) (January), pp. 39-58.

De Meza, D. and Lockwood, B. (1998). 'Does asset ownership always motivate managers? Outside options and the property rights theory of the firm', The Quarterly Journal of Economics, vol. 113(2) (May), pp. 361-86.

Dyer, J.H. (1996). 'Does governance matter? Keiretsu alliances and asset specificity as sources of Japanese competitive advantage', Organization Science, vol. 7(6) (Nov. - Dec.), pp. 649-66.

Ellman, M. (2006). 'Specificity revisited: the role of cross-investments', Journal of Law, Economics, and Organization, vol. 22(1) (March), pp. 234-257.

Evans, R. (2008). 'Simple efficient contracts in complex environments', Econometrica, vol. 76(3) (May), pp. 459-91.

Garvey, G. (1995). 'Why reputation favors joint ventures over vertical and horizontal integration: a simple model', Journal of Economic Behavior and Organization, vol. 28(3) (December), pp. 387-97.

Gibbons, R. (2005). 'Four formal(izable) theories of the firm?', Journal of Economic Behavior and Organization, vol. 58(2) (October), pp. 200-45.

Gilson, R.J., Sabel, C.F. and Scott, R.E. (2009). 'Contracting for innovation: vertical disintegration and interfirm collaboration', unpublished manuscript, Columbia University.

Grossman, S. and Hart, O. (1986). 'The costs and benefits of ownership: a theory of vertical and lateral integration', The Journal of Political Economy, vol. 94(4) (August), pp. 691-719.

Halonen, M. (2002). 'Reputation and the allocation of ownership', The Economic Journal, vol. 112(481) (July), pp. 539-58.

Hansmann, H. (1996). The Ownership of Enterprise, Cambridge: Belknap Press of Harvard University Press.

Hart, O. (1995). Firms, Contracts, and Financial Structure, Oxford: Clarendon Press.

Hart, O. and Moore, J. (1990). 'Property rights and the nature of the firm', The Journal of Political Economy, vol. 98(6) (December), pp. 1119-58.

Holmström, B. (1999). 'The firm as a subeconomy', Journal of Law, Economics, and Organization, vol. 15(1) (March), pp. 74-102.

Holmström, B. and Milgrom, P. (1991). 'Multitask principal-agent analyses: incentive contracts, asset ownership, and job design', Journal of Law, Economics, and Organization, vol. 7(Special Issue) (January), pp. 24-52.

Holmström, B. and Roberts, J. (1998). 'The boundaries of the firm revisited', The Journal of Economic Perspectives, vol. 12(4) (Fall), pp. 73-94. 
Holmström, B. and Tirole, J. (1991). 'Transfer pricing and organizational form', Journal of Law, Economics, and Organization, vol. 7(2) (Autumn), pp. 201-28.

Klein, B., Crawford, R. and Alchian, A. (1978). 'Vertical integration, appropriable rents, and the competitive contracting process', Journal of Law and Economics, vol. 21(2) (October), pp. 297-326.

Klein, B. and Leffler, K. (1981). 'The role of market forces in assuring contractual performance', The Journal of Political Economy, vol. 89(4) (August), pp. 615-41.

Kvaløy, O. (2007). 'Asset specificity and vertical integration', Scandinavian Journal of Economics, vol. 109(3) (September), pp. 551-72.

Levin, J. (2003), 'Relational incentive contracts', The American Economic Review, vol. 93(3) (June), pp. 835-57.

Macher, J.T. and Richman, B.D. (2008). 'Transaction cost economics: an assessment of empirical research in the social sciences', Business and Politics, vol. 10(1), pp. 335-61.

Masten, S.E. and Saussier, S. (2000). 'Econometrics of contracts: an assessment of developments in the empirical literature on contracting', Revue d'Economie Industrielle, vol. 92(2/3), pp. 215-36.

Matouschek, N. (2004). 'Ex post inefficiencies in a property rights theory of the firm', Journal of Law, Economics, and Organization, vol. 20(1) (April), pp. 125-47.

Mol, M.J. (2005). 'Does being R\&D intensive still discourage outsourcing? Evidence from Dutch manufacturing', Research Policy, vol. 34(4) (May), pp. 571-82.

Rajan, R. and Zingales, L. (1998). 'Power in a theory of the firm', The Quarterly Journal of Economics, vol. 113(2) (May), pp. 387-432.

Shelanski, H.A. and Klein, P.G. (1995). 'Empirical research in transaction cost economics: a review and assessment', Journal of Law, Economics, and Organization, vol. 11(2) (October), pp. 335-61.

Spagnolo, G. (1999). 'Social relations and cooperation in organizations', Journal of Economic Behavior E Organization, vol. 38(1) (January), pp. 1-25.

Whinston, M.D. (2003). 'On the transaction cost determinants of vertical integration', Journal of Law, Economics, and Organization, vol. 19(1) (April), pp. 1-23.

Williamson, O. (1975). Markets and Hierarchies: Analysis and Antitrust Implications, New York: Free Press.

Williamson, O. (1985). The Economic Institutions of Capitalism, New York: Free Press.

Womack, J.P., Jones, D.T. and Roos, D. (1990). The Machine that Changed the World, New York: Harper Perennial.

Woodruff, C. (2002). 'Non-contractible investments and vertical integration in the Mexican footwear industry', International Journal of Industrial Organization, vol. 20(8) (October), pp. 1197-1224. 